Guilherme Welter Wendt (2) https://orcid org/0000-0002-9014-6120

\section{Associations between cyberbullying victimization and depressive symptoms in early adolescence}

\author{
Associações entre vitimização por cyberbullying e \\ sintomas de depressão em jovens adolescentes
}

DOI: 10.1590/0047-2085000000312

\begin{abstract}
Objective: To explore distinctive links between specific depressive symptoms (e.g., anhedonia, ineffectiveness, interpersonal problems, negative mood, and negative self-esteem) and cyberbullying victimization (CBV). Methods: This cross-sectional study collected data from 268 adolescents between the ages of 13 to 15 years-old (50.7\% female) who responded to the Children's Depression Inventory $(\mathrm{CDI})$ and to the Revised Cyberbullying Inventory (RCBI). Results: CBV was positively associated with all CDI's domains (anhedonia, ineffectiveness, interpersonal problems, negative mood, and negative self-esteem). Demographics - such as age and gender - were not significant in explaining CBV. However, ineffectiveness $(B=.46, p=.04)$ and negative mood $(B=.37, p<.05)$ significantly predicted CBV. Conclusion: This study reports the first Brazilian examination of the links existing between CBV and specific types of depressive symptoms. Data reinforce the negative impact of cyberbullying experiences on youth's mental health, highlighting stronger associations between negative mood and CBV, which could inform more tailored interventions.
\end{abstract}

KEYWORDS

Adolescent psychiatry, depressive symptoms, cyberbullying, violence.

\section{RESUMO}

Objetivo: Explorar as associações diferenciais entre sintomas depressivos específicos (anedonia, ineficácia, problemas interpessoais, humor deprimido e autoestima negativa) e vitimização por cyberbullying. Métodos: Trata-se de um estudo quantitativo e transversal que coletou dados de 268 adolescentes, com idades entre 13 e 15 anos (50,7\% do sexo feminino), que responderam ao Inventário de Depressão Infantil (CDI) e ao Inventário de Cyberbullying revisado. Resultados: A vitimização por cyberbullying esteve associada positivamente com todos os domínios avaliados pelo CDI (anedonia, ineficácia, problemas interpessoais, humor deprimido e autoestima negativa). Dados demográficos - como idade e sexo - não se mostraram significativos na predição da vitimização por cyberbullying. Todavia, ineficácia $(B=0,46, p=0,04)$ e humor negativo $(B=0,37, p<0,05)$ foram preditores significativos da vitimização por cyberbullying. Conclusão: $\bigcirc$ estudo apresenta os primeiros resultados empíricos brasileiros associando a vitimização por cyberbullying com sintomas específicos de depressão. Os dados reforçam o impacto negativo das experiências de cyberbullying na saúde mental dos jovens, revelando associações mais robustas entre humor deprimido e vitimização por cyberbullying, o que pode subsidiar ações de tratamento e prevenção.

PALAVRAS-CHAVE

Psiquiatria do adolescente, sintomas de depressão, cyberbullying, violência. 


\section{INTRODUCTION}

Cyberbullying (CB) is an intentional, aggressive type of behavior that occur in technology-based interactions. Research on CB has flourished since early 2000's, attempting to identify risk factors associated with $C B$ and use them as evidence to support healthful usage of information and communications technologies (ICT $)^{1,2}$. Data on CB prevalence vary substantially between studies, which can be partly explained by different measures, the time-frame considered, and cut-off scores adopted. Notably, there seems to be higher prevalence of cyberbullying victimization (CBV) rather than cyberbullying perpetration. Possible explanations might include parental attitudes and cultural norms, as well as social desirability bias in self-reporting ${ }^{3}$. In Brazil, a recent study with 669 adolescents indicated that 1.9\% were victims of cyberbullying in the past six months; moreover, traditional bullying was associated with $\mathrm{CBV}^{2}$. Additionally, an independent association between CBV and depression over and above traditional bullying has been reported ${ }^{4}$, which indicates that this type of aggressive behavior has unique features and must be appropriately taken into account by mental health professionals.

Regarding the most established risk factors for CBV, there has been support that depressed individuals - along with traditional bullying victimization - are at greater risk for being victimized $^{2,5-7}$. Interestingly, a meta-analysis reporting on > 400 primary outcomes indicated that offline victimization and internalizing problems - including depression - had stronger effect sizes for becoming a victim of cyberbullying $\left(r^{\prime} s=.42 \text { and } .28, p^{\prime} s<.001 \text {, respectively }\right)^{8}$. More recently, a significant effect size of $r=.20$ was reported linking CBV and depression, based on data including $>33.000$ participants 9 . Age is also associated in increasing the odds ratio of becoming a target of cyberbullying, in which CBV is most likely to occur among younger people?

Nonetheless, evidence from meta-analytical research failed to provide specific associations between CBV and depressive symptoms. In general, studies report on overall associations with internalizing problems ${ }^{8}$ or total scores on measures of depression?. The lack of detailed information might compromise the optimal work of mental health professionals, especially those involved in child and adolescent psychiatry. Therefore, the current investigation attempts to explore distinctive links between specific depressive symptoms (e.g., anhedonia, ineffectiveness, interpersonal problems, negative mood, and negative selfesteem) and CBV in early adolescents. It was predicted that higher occurrence of CBV would be linked to elevated levels of self-reported depression?. The profile of CB victims include a perception of powerlessness (or inefficacy to defend against cyber bullies) ${ }^{3}$, which could then lead to negative mood and problems in one's relationships ${ }^{5,8}$. Hence, another hypothesis stated that negative mood, ineffectiveness and interpersonal problems would predict CBV.

\section{METHODS}

\section{Participants, procedures and design}

This cross-sectional study collected data from 268 adolescents between the ages of 13 to 15 years-old ( $M_{\text {age }}$ $=13.4, S D_{\text {age }}=.70,50.7 \%$ female), enrolled in public schools $6^{\text {th }}$ to $10^{\text {th }}$ grades) from the Porto Alegre metropolitan region, RS. The majority (92.5\%) had an exclusive mobile phone, while $44 \%$ reported possessing their own personal computer. Participants lived with their parents and other relatives $(98.1 \%)$ and $88.3 \%$ of participants had siblings $(M=$ 2.04, SD = 2.44)

The research has been approved by a Research Ethics Committee and followed the recommendations of the Declaration of Helsinki. The researchers contacted ten schools which collaborated in previous projects. After obtaining consent from five schools, the aims of the study were presented to students and parental consent forms were delivered for those interested in taking part. Subsequently, data were collected from participants who had a signed consent form (parents/guardians). A team of psychologists was present during data collection, with the intent of clarifying the research goals and questions, as well as to provide emotional support for students if necessary. Questionnaires were filled at the schools using pen and paper (duration: approximately 30 minutes). Sample size was calculated using G*Power. The procedure taking an average

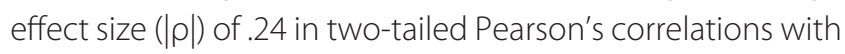
$95 \%$ of power and $a=.05$ or less yielded a minimum sample size of 206 individuals.

\section{Measures}

Children's Depression Inventory ${ }^{10}$ (Cronbach's $a=.84$ ). This 27-item measure assesses depression in youth, covering the following domains: anhedonia, ineffectiveness, interpersonal problems, negative mood, and negative self-esteem. Participants are asked to rate every item, and responses range from 0 (sometimes) to 2 (very often). A higher score indicates a greater severity of depressive symptoms (total possible score $=54$ ). In this study, the Brazilian version was used"1.

Revised Cyberbullying Inventory ${ }^{12}$ (Cronbach's $a=$ .84). The Brazilian adaptation of this instrument assessed participants' involvement with cybervictimization ${ }^{3}$. The cyberbullying victimization subscale contains 14 items. Participants are asked to select the frequency in which they might have been involved with cyber victimization in the past six months using a scale ranging from 0 (never) to 
3 (more than 3 times). The total possible score is 42 , with higher scores indicating greater involvement ${ }^{12}$.

\section{Data analysis}

To account for the study's first hypothesis, bivariate correlations were run to inspect the associations between CBV and depressive symptoms. For the second hypothesis, hierarchical regression analyses were performed (method: enter), taking into account demographic variables in the first step (age and gender). In the second step, variables assessing depressive domains were entered. In the regression procedures, the current study reports on the 95\% bias-corrected and accelerated (BCa) bootstrap intervals with 10.000 samples.

\section{RESULTS}

CBV was positively associated with all CDI's domains (anhedonia, ineffectiveness, interpersonal problems, negative mood, and negative self-esteem; Table 1).
Table 2 reports the results from hierarchical linear regression models examining the role of age, gender, and depression in predicting CBV in Brazilian early adolescents. Demographics (Block 1) were not significant in explaining the dependent variable. However, ineffectiveness ( $B=.46, p=.04$ ) and negative mood $(B=.37, p<.05)$ significantly predicted $C B V$ (Block 2).

\section{DISCUSSION}

This study reports the first Brazilian examination of the links existing between CBV and specific types of depressive symptoms. In general, data confirmed the first hypothesis and corroborates what has been noted internationally in terms of a positive association between CBV and depression ${ }^{4,6,8,9}$. However, results indicated differential associations for some depressive traits in comparison to others, which might add to the current understanding associating CBV to one's deteriorated mental health 2,13,14.

Table 1. Correlations between cyberbullying victimization and depression

\begin{tabular}{|c|c|c|c|c|c|c|c|c|}
\hline & & 1 & 2 & 3 & 4 & 5 & 6 & 7 \\
\hline \multirow[t]{2}{*}{ 1. Cyberbullying victimization } & Pearson's r & - & & & & & & \\
\hline & $p$-value & & & & & & & \\
\hline \multirow[t]{4}{*}{ 2. Anhedonia } & Pearson's r & .29 & - & & & & & \\
\hline & $\mathrm{p}$-value & $<.001$ & - & & & & & \\
\hline & Upper $95 \% \mathrm{Cl}$ & .39 & - & & & & & \\
\hline & Lower $95 \% \mathrm{Cl}$ & .17 & - & & & & & \\
\hline \multirow[t]{4}{*}{ 3. Ineffectiveness } & Pearson's r & .28 & .50 & - & & & & \\
\hline & $p$-value & $<.001$ & $<.001$ & - & & & & \\
\hline & Upper $95 \% \mathrm{Cl}$ & .38 & .59 & - & & & & \\
\hline & Lower $95 \% \mathrm{Cl}$ & .16 & .41 & - & & & & \\
\hline \multirow[t]{4}{*}{ 4. Interpersonal problems } & Pearson's r & .26 & .45 & .47 & - & & & \\
\hline & $p$-value & $<.001$ & $<.001$ & $<.001$ & - & & & \\
\hline & Upper 95\% Cl & .37 & .54 & .56 & - & & & \\
\hline & Lower $95 \% \mathrm{Cl}$ & .14 & .34 & .37 & - & & & \\
\hline \multirow[t]{4}{*}{ 5. Negative mood } & Pearson's r & .31 & .54 & .52 & .49 & - & & \\
\hline & $\mathrm{p}$-value & $<.001$ & $<.001$ & $<.001$ & $<.001$ & - & & \\
\hline & Upper $95 \% \mathrm{Cl}$ & .41 & .62 & .61 & .58 & - & & \\
\hline & Lower $95 \% \mathrm{Cl}$ & .19 & .45 & .43 & .39 & - & & \\
\hline \multirow[t]{4}{*}{ 6. Negative self-esteem } & Pearson's r & .14 & .45 & .61 & .39 & .50 & - & \\
\hline & $\mathrm{p}$-value & .02 & $<.001$ & $<.001$ & $<.001$ & $<.001$ & - & \\
\hline & Upper $95 \% \mathrm{Cl}$ & .26 & .54 & .68 & .48 & .59 & - & \\
\hline & Lower $95 \% \mathrm{Cl}$ & .02 & .35 & .52 & .28 & .40 & - & \\
\hline \multirow[t]{4}{*}{ 7. Depression (total) } & Pearson's r & .33 & .82 & .76 & .70 & .81 & .73 & - \\
\hline & $p$-value & $<.001$ & $<.001$ & $<.001$ & $<.001$ & $<.001$ & $<.001$ & - \\
\hline & Upper 95\% Cl & .44 & .85 & .81 & .75 & .85 & .78 & - \\
\hline & Lower $95 \% \mathrm{Cl}$ & .21 & .77 & .71 & .63 & .76 & .67 & - \\
\hline
\end{tabular}

Note. In bold, significant correlations between cyberbullying victimization and depression are highlighted. 
Table 2. Hierarchical linear regression examining the role of age, gender, and depression in predicting cyberbullying victimization in Brazilian early adolescents

\begin{tabular}{|c|c|c|c|c|c|}
\hline & B & SE & p & 95\% BCa Cl & $R_{A d j}^{2}$ \\
\hline \multicolumn{6}{|l|}{ Block 1} \\
\hline Age & .51 & .36 & .16 & $-.18,1.23$ & \\
\hline Gender & -.10 & .50 & .84 & $-1.1, .87$ & \\
\hline Fit statistics & $F(2,242)=1.1$, & & & & .001 \\
\hline \multicolumn{6}{|l|}{ Block 2} \\
\hline Age & .38 & .33 & .26 & $-.6,1.01$ & \\
\hline Gender & -.58 & .46 & .22 & $-1.45, .37$ & \\
\hline Anhedonia & .21 & .15 & .17 & $-.07, .50$ & \\
\hline Ineffectiveness & .46 & .22 & .037 & $.05, .88$ & \\
\hline Interpersonal problems & .16 & .26 & .51 & $-.35, .66$ & \\
\hline Negative mood & .37 & .18 & .047 & $.02, .75$ & \\
\hline Negative self-esteem & -.34 & .20 & .08 & $-.71, .06$ & \\
\hline Fit statistics & $F\left({ }_{7,237}\right)=5.86$ & & & & .12 \\
\hline
\end{tabular}

Notes. In bold, significant predictors are highlighted. BCa Cl: Bias-corrected and accelerated confidence intervals; Durbin Watson = 1.87; Variance Inflation Factor range $=1.002$ to 1.931 .

First, the relationship between depression total scores with CBV depicted in Table 1 was higher in comparison with previous investigations conducted in developed countries (e.g., Australia and Austria; $r=.18)^{4}$. At glance, this could suggest that Brazilian youth are perhaps experiencing stronger consequences related to CBV. However, scales used between studies varied. Wang and collaborators ${ }^{14}$ reported adopting the Center for Epidemiologic Studies Depression Scale, while Perren and collaborators ${ }^{4}$ included different measures for depression in their study. Nonetheless, scholars have emphasized that cultural mechanisms might be closely implicated in cyberbullying behaviors, with reports indicating that social norms could facilitate the occurrence of ICT-mediated aggression ${ }^{4,9}$. Moreover, cultural fluctuations in parental attitudes in relation to youth ICT usage could predispose certain individuals to greater risks for cyberbullying involvement ${ }^{3}$. Thus, differences between studies could reflect particularities seen in the Brazilian context.

Another hypothesis stated that negative mood, ineffectiveness, and interpersonal problems would predict CBV. This hypothesis was partly confirmed. The significant role of negative mood and ineffectiveness in predicting CBV deserve further consideration, especially when prevention and intervention strategies are to be designed. Qualitative data suggested that CBV could cause stronger negative feelings, fear, and helplessness ${ }^{15}$, and the current study added empirical support to these associations. Importantly, the fact that ineffectiveness was significant - along with negative mood - in the regression analyses stresses the importance of cognitive-behavioral strategies in targeting CBV, such as emotion-regulation and problem-solving. The associations between CBV with ineffectiveness and negative mood reinforce that imbalance of power is a major criterion in cyberbullying research and could explain the dynamics seen in $\mathrm{CBV}^{16}$. Indeed, Menesini and collaborators reported on data from $>2.000$ European adolescents who were asked to judge the relevance of terms associated with cyberbullying (i.e., anonymity, imbalance of power, intentionality, public versus private, and repetition). A twodimensional solution involving imbalance of power and intentionality explained $96 \%$ of the variance ${ }^{16}$, suggesting that, as seen in traditional bullying 3,5 , cyberbullying victims relate imbalance of power with negative mood and ineffectiveness. Therefore, both inefficacy and depression might be associated with youth's lack of power against cyberbullying perpetrators.

Beyond the study's immediate goals, there are some noteworthy implications for understanding youth mental health in the national context. Remarkably, levels of depression were below the international cut-off scores $^{10}$, yet very similar to previous report from Brazilian adolescents $^{13}$. This suggests a pattern of stability in these symptoms across studies. Moreover, compared to reports that have used the $R C B I$ to measure cyberbullying occurrence, means for CBV were about half the value reported in developed countries, such as the United Kingdom ${ }^{5}$. Investigations examining possible explanations for these discrepancies between countries are needed, as well as efforts in exploring other psychiatric outcomes associated with CBV. In addition, the limitations of this study must be considered, mainly in relation to selfreported measures and the cross-sectional design. While the former carries the risk of eliciting socially desirable responses, the latter impedes the comprehension of clear cause and effect patterns. 


\section{CONCLUSION}

This investigation showed that ineffectiveness and negative mood were significant in predicting cyberbullying victimization in early adolescents. The results reported might support future studies on the efficacy of interventions and prevention programs for CBV, both at individual and group levels.

\section{INDIVIDUAL CONTRIBUTIONS}

The author has contributed in the study's conception and design, data acquisition, analysis, interpretation of results, writing and approval of the final version.

\section{CONFLICT OF INTEREST}

The author has no conflict of interest to report.

\section{REFERENCES}

1. Palermiti AL, Servidio R, Bartolo MG, Costabile A. Cyberbullying and self-esteem: An Italian study. Comp Hum Beh. 2017;69:136-41.

2. Vieira MA, Rønning JA, Mari I de J, Bordin IA. Does cyberbullying occur simultaneously with other types of violence exposure? Braz J Psychiatry. 2019;41(3):234-7.

3. Wendt G. Cyberbullying em adolescentes brasileiros [dissertation]. São Leopoldo: Universidade do Vale do Rio dos Sinos; 2012
4. Perren S, Dooley J, Shaw T, Cross D. Bullying in school and cyberspace: Associations with depressive symptoms in Swiss and Australian adolescents. Child Adol Psych Men. 2010;4(1):28.

5. Brewer G, Kerslake J. Cyberbullying, self-esteem, empathy and loneliness. Comp Hum Beh. 2015:48:255-60

6. Mitchell SM, Seegan PL, Roush JF, Brown SL, Sustaíta MA, Cukrowicz KC. Retrospective cyberbullying and suicide ideation: The mediating roles of depressive symptoms, perceived burdensomeness, and thwarted belongingness. J Interpers Violence. 2018;33(16):2602-20.

7. Cassidy W, Faucher C, Jackson M. Cyberbullying among youth: A comprehensive review of current international research and its implications and application to policy and practice. Sch Psych Int. 2013;34(6):575-612.

8. Guo S. A meta-analysis of the predictors of cyberbullying perpetration and victimization: Cyberbullying perpetration and victimization. Psychol Sch. 2016;53(4):432-53.

9. Chen L, Ho SS, Lwin MO. A meta-analysis of factors predicting cyberbullying perpetration and victimization: From the social cognitive and media effects approach. New Media Soc. 2017;19(8):1194-213

10. Kovacs M. Children's depression inventory: Manual. North Tonawanda: Multi-Health Systems; 1992

11. Hutz CS, Giacomoni C. Adaptação brasileira do inventário de depressão infantil [unpublished manuscript]. Porto Alegre: Universidade Federal do Rio Grande do Sul; 2000.

12. Topсu Ç, Erdur-Baker Ö. The Revised Cyber Bullying Inventory (RCBI): Validity and reliability studies. Procedia Soc Behav Sci. 2010;5:660-4.

13. Reppold C. Estilo parental percebido e adaptação psicológica de adolescentes adotados [dissertation]. Porto Alegre: Universidade Federal do Rio Grande do Sul; 2001.

14. Wang J, Nansel TR, lannotti RJ. Cyber and traditional bullying: Differential association with depression. J Adolesc Health. 2011;48(4):415-7.

15. Spears B, Slee P, Owens $L$, Johnson B. Behind the scenes and screens: Insights into the human dimension of covert and cyberbullying. J Psych. 2009;217(4):189-96.

16. Menesini E, Nocentini A, Palladino BE, Frisén A, Berne S, Ortega-Ruiz R, et al. Cyberbullying definition among adolescents: A comparison across six European countries. Cyberpsychol Behav Social Netw. 2012;15(9):455-63. 